RESEARCH REPORT

\title{
Gender differences in socioeconomic inequality in mortality
}

\author{
C A Mustard, J Etches
}

J Epidemiol Community Health 2003;57:974-980

See end of article for authors' affiliations

.....................

Correspondence to: Cameron A Mustard, Institute for Work \& Health, 481 University Avenue, Toronto, Ontario, Canada; cmustard@iwh.on.ca

Accepted for publication 21 May 2003

\begin{abstract}
Objectives: There is uncertainty about whether position in a socioeconomic hierarchy confers different mortality risks on men and women. The objective of this study was to conduct a systematic review of gender differences in socioeconomic inequality in risk of death.

Methods: This research systematically reviewed observational cohort studies describing all cause or cause specific mortality for populations aged 25-64 in developed countries. For inclusion in the review, mortality had to be reported stratified by gender and by one or more measures of socioeconomic status. For all eligible studies, five absolute and six relative measures of the socioeconomic inequality in mortality were computed for male and female populations separately.

Results: A total of 136 published papers were reviewed for eligibility, with 58 studies deemed eligible for inclusion. Of these eligible studies, 20 papers published data that permitted the computation of both absolute and relative measures of inequality. Absolute measures of socioeconomic mortality inequality for men and women generally agreed, with about $90 \%$ of studies indicating that male mortality was more unequal than female mortality across socioeconomic groups. In contrast, the pattern of relative inequality results across the 20 studies suggested that male and female socioeconomic inequality in mortality was equivalent.

Conclusions: Inferences about gender differences in socioeconomic inequality in mortality are sensitive to the choice of inequality measure. Wider understanding of this methodological issue would improve the clarity of the reporting and synthesis of evidence on the magnitude of health inequalities in populations.
\end{abstract}

$\mathrm{T}$ his review takes as its starting point the apparent empirical regularity of a greater inequality in male mortality over socioeconomic groups relative to female mortality in the developed economies..$^{1-3}$ Before considering the relevant causal mechanisms for this apparent regularity, the fundamental issue of measurement artefact needs to be ruled out as a possible explanation. Error may arise in the measurement of socioeconomic status among men and women. There is a long tradition of concern in population health studies that the position in a social or economic hierarchy is measured with less precision among women than among men. ${ }^{245}$ In addition, conclusions concerning the presence of gender differences in inequality may depend upon the choice of the summary of measure of inequality applied in the study. This last issue is the subject of this review.

Five groups have provided critical reviews of measures of inequality in population health studies, with the most recent contributions from Anand ${ }^{6}$ and Etches. ${ }^{7}$ Previously, Mackenbach et al identified 12 types of summary measures of inequality, and empirically compared the performance of these measures in summarising the distribution of health in relation to social hierarchy (mortality in Finland in relation to occupational class and self reported morbidity by educational level in the Netherlands). ${ }^{8}$ The authors concluded that an optimal or ideal inequality measure could not be determined, and that it was advisable to apply different measures. Manor et al compared the performance of three measures of inequality in relation to two measures of social hierarchy (class at birth and educational qualifications) and concluded that inferences did not differ substantially using the three measures of inequality. ${ }^{9}$ Wagstaff et al reviewed the properties of inequality measures in the measurement of health differences and gave an emphatic recommendation to measures from the class of slope or concentration curve indices. ${ }^{10}$
While gender specific mortality rates or mortality ratios stratified by socioeconomic status are frequently reported in demographic or epidemiological studies of developed country populations, we were unable to identify a review that systematically evaluated these studies to address the question of whether position in the socioeconomic hierarchy conferred different mortality risks for men and women. To address this deficiency, we undertook a systematic review of cohort studies in developed economy populations aged 25-64 that described all cause or cause specific mortality separately for men and women by one or more measures of socioeconomic status.

\section{METHODS}

To establish the sample for this review, we systematically searched the published literature for observational cohort studies describing all cause or cause specific mortality for populations aged 25-64 in developed economy countries published in the period 1970 to 2000. The search strategy applied a formal search of three concepts: mortality, gender and socioeconomic status. Formal MeSH terms were applied (mortality, sex, social class, socieconomic factors) as well as relevant variant keywords, such as "gender" as a substitute for the MeSh term "sex". Keyword indexing, titles, and abstracts were searched in a range of electronic databases, with most of the published studies located in Medline, Healthstar (now consolidated in PubMed) and Ageline. Hand searches of bibliographies identified in relevant published work were also conducted.

Of the 136 potentially eligible studies identified in the search of published work, abstracts or the complete report were then reviewed by two reviewers for confirmation that the information in the published study reported mortality stratified both by gender and by one or more measures of socioeconomic status. After this screening, 58 studies were retained as potentially eligible for inclusion. The final 
inclusion criteria required that the data reported in the study supported the computation of both an absolute and a relative measure of inequality for at least one of the six classes of candidate inequality measures of interest in this study. In cases where the two reviewers' differed in their judgment of the eligibility of the study, a third reviewer (CM) participated in the review.

After this final evaluation, a total of 20 studies were deemed eligible for inclusion in the study. A number of research studies that directly focused on the question of interest in this review were deemed ineligible because the reported data in the published study did not support the computation of both absolute and relative inequality measures (see, for example, various studies ${ }^{121-22}$ ).

\section{Inequality measures}

The six classes of inequality measures used in this review have been critically evaluated in a number of previous reviews. ${ }^{6-10}$ Each of the six classes of inequality measures have an absolute form and a relative form, with the exception of Agresti's $\alpha$, which measures inequality only in a relative form. In absolute measures of inequality, the magnitude of mortality differences between comparison groups is retained in the computation of the measure. In the case of relative measures, information on the magnitude of mortality differences is not retained in the computation of the measure. Relative measures express the dispersion across socioeconomic strata as a proportion of the mean or value for a particular group. Relative and absolute measures can disagree as to which group has more or less inequality. This property is illustrated in the following simple example. Suppose men and women are classified into two groups; high socioeconomic status and low socioeconomic status. For men in the high socioeconomic status group, the mortality rate is 2/ 1000 person years, and for men in the low socioeconomic group, the mortality rate is $4 / 1000$ years. For women, the comparable values are $1 / 1000$ and 2/1000. On the basis of a simple rate difference (an absolute measure), the inequality observed for men (2/1000 person years) is twice that observed for women (1/1000 person years). However, if estimated using a relative inequality measure, the rate ratio, the observed inequality for men (4/1000 divided by $2 / 1000)$ is identical to the rate ratio for women (2/1000 divided by $1 /$ 1000).
In addition, there are important normative assumptions involved in choosing between these two forms, which we return to in the discussion. The measures are distinguished by a number of characteristics, as outlined in table 1 .

For the 20 eligible studies, the five absolute and six relative measures of the socioeconomic inequality in mortality were computed for male and female populations separately. The one exception to this statement is the study by Pamuk, ${ }^{23}$ for which only the slope index of inequality was reported. We chose to include this study because the authors reported both absolute and relative forms of this inequality measure. A number of studies reported results for different age groups, ${ }^{24-29}$ for different countries ${ }^{30}$ and for different time periods. ${ }^{31-33}$ In these cases, inequality measures were computed for each relevant gender comparison, resulting in some studies contributing more than one series of 11 inequality measures (five absolute measures and six relative measures) (see table 2). In addition, seven studies reported gender specific mortality relative to more than one measure of socioeconomic status. $^{24} 2536-384142$

\section{Statistical analysis}

Formal statistical inference tests that are appropriate to meta-analysis were not conducted in this review. The appropriate test in this review would apply a test of common dose-response across the ordinal structure of the independent variable, socioeconomic status. ${ }^{43}$ In our opinion, the measures of socioeconomic status used across the range of studies in this sample is too heterogeneous in conception and measurement to be incorporated in a formal meta-analytic hypothesis test. The results reported in this review are provided within a qualitative appraisal framework.

\section{RESULTS}

Of the 20 studies eligible for inclusion in this review, Denmark $^{30}$ and Norway ${ }^{30}$ were each represented in a single study, the United Kingdom was represented in four studies, $^{23} 303236$ and the United States, ${ }^{24} 2728313841$ Finland, 263033353740 and Sweden 2530343942 were each represented in six studies.

There were a wide range of measures of socioeconomic status reported in the eligible studies. Occupation was the most frequently reported measure, followed by education, a composite measure of social position, and household income.

Table 1 Measures of inequality, classified by absolute or relative form

\begin{tabular}{|c|c|c|c|c|c|c|c|}
\hline Measure & $\begin{array}{l}\text { Absolute/ } \\
\text { relative }\end{array}$ & Bi/univariate & Health measure & SES measure & $\begin{array}{l}\text { Type of inequality } \\
\text { measure* }^{*}\end{array}$ & $\begin{array}{l}\text { Detects reverse } \\
\text { gradients }\end{array}$ & $\begin{array}{l}\text { Detects group } \\
\text { size }\end{array}$ \\
\hline Rate difference & a & b & rates & extreme groups & e & y & $\mathrm{n}$ \\
\hline Rate ratio & $\mathrm{r}$ & $\bar{b}$ & rates & extreme groups & $\mathrm{e}$ & y & $n$ \\
\hline $\begin{array}{l}\text { Population attributable } \\
\text { risk }\end{array}$ & a & b & rates & dichotomous & $\mathrm{s}$ & y & $\mathrm{n}$ \\
\hline $\begin{array}{l}\text { Population attributable } \\
\text { risk }\end{array}$ & $\mathrm{r}$ & $b$ & rates & dichotomous & s & y & $n$ \\
\hline Index of dissimilarity & a & b & $\begin{array}{l}\text { usually cases/ } \\
\text { deaths }\end{array}$ & nominal & $\mathrm{h}$ & $\mathrm{n}$ & y \\
\hline Index of dissimilarity & $r$ & b & $\begin{array}{l}\text { usually cases/ } \\
\text { deaths }\end{array}$ & nominal & $\mathrm{h}$ & $\mathrm{n}$ & y \\
\hline $\begin{array}{l}\text { Slope index of } \\
\text { inequality }\end{array}$ & $a$ & b & rates & ordinal & $\mathrm{i}$ & y & $y$ \\
\hline $\begin{array}{l}\text { Slope index of } \\
\text { inequality }\end{array}$ & $r$ & b & rates & ordinal & $\mathrm{i}$ & y & y \\
\hline Concentration index & a & b & $\begin{array}{l}\text { Ratio scale } \\
\text { measure }\end{array}$ & ordinal & $\mathrm{i}$ & y & y \\
\hline Concentration index & $r$ & b & $\begin{array}{l}\text { Ratio scale } \\
\text { measure }\end{array}$ & ordinal & $\mathrm{i}$ & y & y \\
\hline Agresti's $\alpha$ & $r$ & b & $\begin{array}{l}\text { Ordinal scale } \\
\text { measure }\end{array}$ & ordinal & $\mathrm{i}$ & y & y \\
\hline
\end{tabular}

*Type of inequality measure: (e) effect, (s) shorffall, (h) heterogeneity, (i) inequality. For detailed description of measures see various references. ${ }^{6}-10$ 


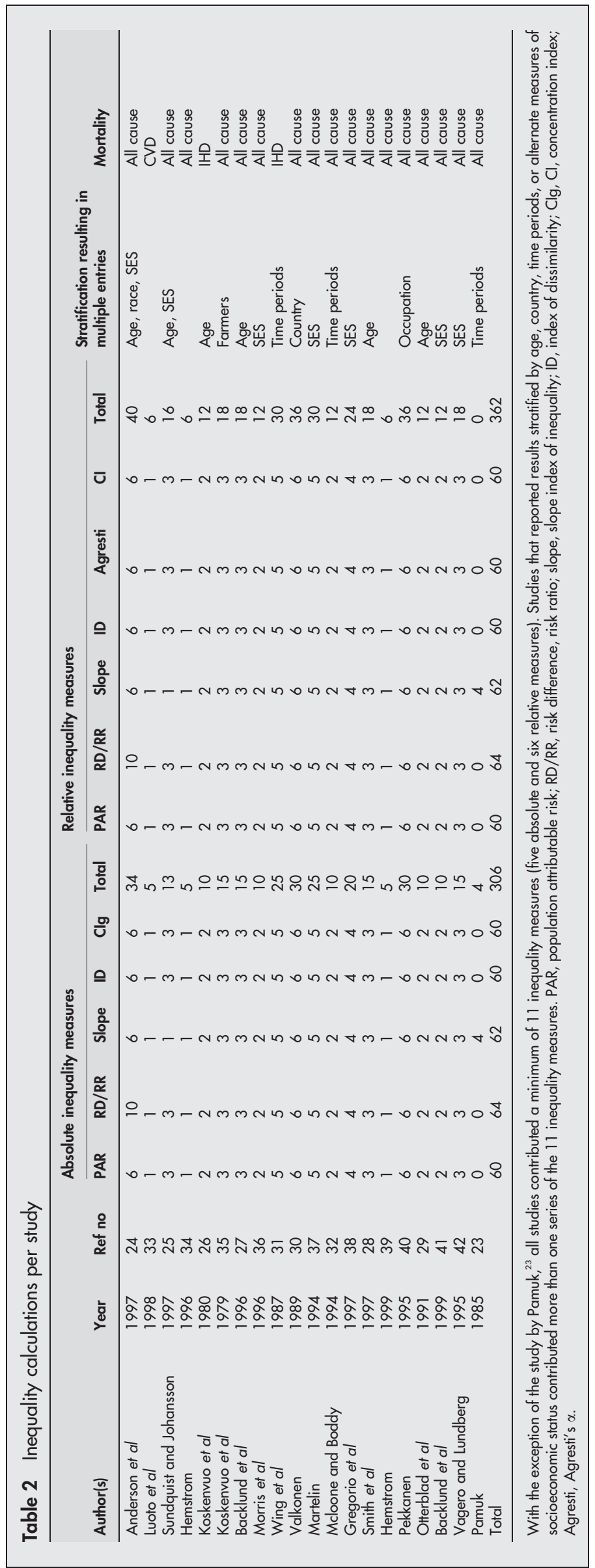


Table 3 Proportion of comparisons where men experience more inequality than women

\begin{tabular}{|c|c|c|c|c|c|c|}
\hline \multirow{3}{*}{$\begin{array}{l}\text { Inequality measure } \\
\text { Measure }\end{array}$} & \multicolumn{3}{|c|}{ Absolute } & \multicolumn{3}{|c|}{ Relative } \\
\hline & \multicolumn{3}{|c|}{ Denominator form } & \multicolumn{3}{|c|}{ Denominator form } \\
\hline & PY & persons & combined & $\mathbf{P Y}^{*}$ & persons & combined \\
\hline $\mathrm{RD} / \mathrm{RR}$ & 0.95 & 1.00 & 0.97 & 0.70 & 0.67 & 0.69 \\
\hline PAR & 0.94 & 0.96 & 0.95 & 0.55 & 0.52 & 0.53 \\
\hline ID & 0.97 & 1.00 & 0.98 & 0.52 & 0.48 & 0.50 \\
\hline Slope & 0.91 & 0.86 & 0.89 & 0.58 & 0.40 & 0.50 \\
\hline $\mathrm{Cl}$ & 0.91 & 0.96 & 0.93 & 0.61 & 0.44 & 0.53 \\
\hline Agresti & NA & NA & NA & 0.55 & 0.44 & 0.50 \\
\hline
\end{tabular}

PY, person years; RD/RR, risk difference, risk ratio; PAR, population attributable risk; ID, index of dissimilarity; slope, slope index of inequality; $\mathrm{Cl}$, concentration index; Agresti, Agresti's $\alpha$.

No single socioeconomic status measure was represented in all studies in this review.

As described in table 3, there was both consistency and contradiction in the findings across the 20 studies in the comparison of male and female inequality. Across the five classes of absolute measures, men were found to have greater socioeconomic inequality in mortality than women. This result obtained whether the comparison was based on person years or person denominators. However, the results from the comparison of relative measures of inequality generally contradicted the findings of the comparison of absolute measures of inequality. In the case of most classes of relative inequality, the socioeconomic inequality in male and female mortality was virtually identical. The one exception to this general statement was comparisons of male and female inequality estimated from the rate ratio comparison.

These contrasting findings between the absolute and relative measures are displayed in table 4, which reports the mean inequality estimates for men and for women, stratified by the class of inequality measure. For example, the mean rate difference between the highest and lowest socioeconomic groups is 609 per 100000 person years for men and 234 for women, while the mean rate ratios for person year data show a lesser gender difference at 1.77 and 1.59 respectively. The mean absolute PAR is 311 per 100000 person years for men and 128 for women, again showing a more than twofold greater inequality among men, while the relative version of the PAR gives more equal seeming values of 0.25 and 0.21 respectively. The strong dominance of male inequality in the mean inequality estimates derived from absolute measures is not present in the mean inequality estimates based on relative measures.

The consistency of these results in relation to the measure of socioeconomic status used in the study is reported in table 5. In the case of the absolute measures, the finding of a dominance of male inequality over female inequality is found across all measures of socioeconomic status. In the case of the relative inequality measures, the results are more uneven. There is little important difference in inequality estimates based on individual measures of socioeconomic status and household or neighbourhood measures.

\section{DISCUSSION}

In this systematic review of mortality in the developed economies, about $90 \%$ of studies reported that male mortality was more unequal over socioeconomic groups than female mortality when evaluated by absolute measures of inequality. In contrast, male and female socioeconomic mortality inequalities were shown to be essentially identical when evaluated by relative measures of inequality.

Understanding the methodological basis for the very different conclusions to be drawn from a comparison of male and female socioeconomic mortality inequality based on absolute or on relative measures may well resolve a longstanding confusion in the literature. While a systematic review of socioeconomic mortality differences by gender has not been previously conducted, many authors have noted a prevailing view in the literature that the socioeconomic gradient in mortality is weaker in women. ${ }^{23}$ This view seems to be an accurate appraisal based on absolute measures of inequality. However, this view is contradicted by the pattern of findings based on relative measures of inequality. Inferences about health inequalities between groups are sensitive to the choice of inequality measure.

A key implication of these distinct conclusions is to focus attention on the determinants of the persistent and substantial difference in life expectancy between men and women that underlie the gender differences in inequality

Table 4 Mean inequality estimates, stratified by class of inequality measure and gender (equal weighting of observations)

\begin{tabular}{|c|c|c|c|c|c|c|c|c|}
\hline \multirow[b]{3}{*}{ Inequality measure } & \multicolumn{4}{|l|}{ Absolute* } & \multicolumn{4}{|l|}{ Relative } \\
\hline & \multicolumn{2}{|l|}{ person years } & \multicolumn{2}{|l|}{ persons } & \multicolumn{2}{|c|}{ person years } & \multicolumn{2}{|l|}{ persons } \\
\hline & Men & Women & Men & Women & Men & Women & Men & Women \\
\hline Rate difference/ratio† & 609 & 234 & 35 & 17 & 1.77 & 1.59 & 1.83 & 1.77 \\
\hline Population attributable risk $\ddagger$ & 311 & 128 & 15 & 7 & 0.25 & 0.21 & 0.23 & 0.21 \\
\hline Index of dissimilarity§ & 96.8 & 41.7 & 5.01 & 2.87 & 0.0766 & 0.0749 & 0.078 & 0.0835 \\
\hline Slope index of inequality & -829 & -345 & -54.2 & -41.6 & -0.64 & -0.62 & -2.36 & -3.67 \\
\hline Concentration indices ${ }^{* *}$ & -0.00109 & -0.00046 & -0.00613 & -0.00332 & -0.086 & -0.083 & -0.091 & -0.096 \\
\hline Agresti's $\alpha \dagger \dagger$ & NA & NA & NA & NA & 1.36 & 1.35 & 1.37 & 1.408 \\
\hline
\end{tabular}

*Units of measurement for absolute measures are deaths per 100000 (person years) and deaths per 10000 (persons). †Absolute, the difference between the rates for the least and most advantaged socioeconomic groups; relative, the ratio of these rates. $¥$ Absolute, the decrease in the population rate that would occur if all groups had the rate of the most advantaged socioeconomic group; relative, this decrease as a proportion of the population rate. $\S A b s o l u t e$, the number of deaths that must be "redistributed" to achieve equality; relative, this value as a proportion of the total number of deaths. "Absolute, the difference between the predicted rates for the most and least advantaged persons based on a weighted regression of socioeconomic group rates on socioeconomic status; relative, this difference as a proportion of the population rate. ${ }^{* *}$ Absolute, twice the area between the generalised concentration curve of health and socioeconomic status and the line of equality; relative, this value as a proportion of the population rate. $+\uparrow$ Relative, an odds ratio generalised to ordinal data. 
Table 5 Proportion of comparisons where men experience more inequality than women, stratified by measure of socioeconomic status and absolute compared with relative inequality measures

\begin{tabular}{|c|c|c|c|c|}
\hline & Absolute & $\mathbf{N}^{*}$ & Relative & $\mathbf{N}^{*}$ \\
\hline \multicolumn{5}{|l|}{ Individual measures } \\
\hline Education & 0.90 & 40 & 0.70 & 50 \\
\hline Occupation & 0.93 & 88 & 0.42 & 110 \\
\hline Income & 0.88 & 16 & 0.70 & 20 \\
\hline Health status & 1.00 & 3 & 0.00 & 4 \\
\hline Social position & 0.89 & 28 & 0.13 & 30 \\
\hline Poverty & 1.00 & 12 & 0.67 & 15 \\
\hline Total & 0.92 & 187 & 0.48 & 229 \\
\hline \multicolumn{5}{|c|}{$\begin{array}{l}\text { Household or } \\
\text { neighbourhood measures }\end{array}$} \\
\hline Housing tenure & 1.00 & 3 & 0.00 & 4 \\
\hline Household income & 1.00 & 16 & 0.05 & 20 \\
\hline Housing condition & 1.00 & 4 & 1.00 & 5 \\
\hline Standard of equipment & 1.00 & 4 & 1.00 & 5 \\
\hline Area deprivation & 1.00 & 12 & 1.00 & 15 \\
\hline Area income & 1.00 & 12 & 0.87 & 15 \\
\hline Area school performance & 1.00 & 4 & 1.00 & 5 \\
\hline Total & 1.00 & 55 & 0.64 & 69 \\
\hline
\end{tabular}

portrayed by absolute measures. An understanding of the greater absolute socioeconomic mortality risk experienced by men will be informed by an understanding of the causes of higher male mortality. The causes of death with the greatest socioeconomic inequalities tend to be more common in men (for example, cardiovascular disease and accidents and violence) and conversely, causes of death that dominate female mortality tend to have shallower socioeconomic inequalities (for example, neoplasms). ${ }^{144}$ Koskinen found that an analysis adjusting for gender differences in cause of death eliminated the pattern of a steeper male socioeconomic mortality gradient, estimated using the absolute measure of the index of dissimilarity. ${ }^{1}$

The finding of an equivalent relative mortality differential for men and women in relation to position in the socioeconomic hierarchy suggests that the pathways by which socioeconomic status influences the distribution of experiences and exposures with adverse effects on health are broadly equivalent for men and women. These pathways, acting through material conditions, psychological environments, and health behaviours, seem to have similar relative impacts (in aggregate) on male and female mortality risks.

At the same time, there has been a relative lack of research attention paid to examining gender differences in the pathways that produce socioeconomic mortality gradients. Male and female differences in labour market experiences have been considered as one potential explanation. For example, Waldron has suggested that perhaps $5 \%-10 \%$ of the excess male mortality rate in the United States can be attributed to greater male exposure to risk of work accidents and chemical or physical occupation hazards as a result of the sex distribution of occupations held. ${ }^{45}$ Based on analyses of mortality in the French labour force, Vallin has offered a similar conclusion that differences between men and women in the rate of labour force participation has no important effect on the male/female mortality ratio. ${ }^{44}$

In addition to the potential role of material conditions and labour market experiences in contributing to the higher rates of male mortality, gender differences in psychosocial experiences may deserve attention. While there is a well established research tradition examining the role of social relationship in buffering a person's psychological and physiological response to external demand and challenge, the evidence for gender differences in the relation between psychosocial resources and risk of mortality is inconsistent. The Alameda County study found equivalently increased risks of death for men and women with low social interaction scores. ${ }^{46}$ This finding of an equivalent risk for both men and women has been reported from other studies. ${ }^{47}{ }^{48}$ However, a number of other studies have reported higher mortality risks for men with low social support resources relative to women who report similar degrees of social isolation..$^{25} 495$ Further work on gender differences in the distribution of psychosocial resources over the life course and on the relation between psychosocial conditions and neuroendocrine function promises to enhance understanding of the potential for psychosocial environments to exert different influences on the health of men and women. ${ }^{51}{ }^{52}$

Health behaviours, especially cigarette use and excess alcohol consumption, have been shown to account for a meaningful share of excess male mortality. For example, higher male cigarette use in North America over the period 1940-80 has been estimated to be responsible for about one half of the sex difference in total mortality, ranging from about two thirds of the sex mortality differential at age 40 to about one quarter of the differential at age $80 .^{45}$ Further insight into the impact of gender differences in alcohol consumption on male and female socioeconomic mortality gradients has been provided by a Finnish study. ${ }^{53}$ In this work, mortality data have been used to classify deaths by cause, with an emphasis on identifying alcohol related deaths and occupational information on the death record has been used to compare the proportion of alcohol related deaths across the occupational hierarchy. Compared with men in the highest non-manual occupations, an estimated $9 \%$ of the excess mortality among men in lower non-manual occupations and $14 \%$ of excess deaths among men in manual occupations were attributed to alcohol related mortality. In contrast, the respective proportions for women were 3\% and $4 \%$. Removing the contribution of alcohol related mortality to the male socioeconomic mortality gradient does reduce, but does not eliminate the sex differential in socioeconomic mortality gradients.

\section{WHICH MEASURE IS BEST?}

This review has offered a comparison of the performance of six classes of inequality measures. The different characteristics of these measures have potential importance for their 
performance in measuring inequality. All six classes of inequality measures have the capacity to detect the direction of a socioeconomic gradient with the exception of classes of measures based on the index of dissimilarity (ID). Use of the ID measure, while attractive for the property of incorporating the size of population strata in the calculation of group inequality, is vulnerable to this indifference to the direction of the socioeconomic gradient. Four of the six classes of measures incorporate information on the size of population strata. The potential shortcomings of the two classes of measures that do not incorporate the size of population strata (PAR and rate or ratio difference measures) should be recognised.

Consistent with recommendations provided earlier by Pamuk $^{23}$ and by Wagstaff, ${ }^{10}$ we find two classes of measures to have optimal measurement properties for the description and comparison of health inequalities in populations. Slope measures of inequality and concentration index measures of inequality share the following optimal properties: (1) they can be computed on both an absolute and relative basis (which we generally recommend as an ideal practice), (2) they can make use of the full information available from an ordinal level measures of socioeconomic status, which respects the conceptual premise of the construction of social hierarchies in the developed economies, (3) they incorporate differences in the size of populations across the socioeconomic strata, and (4) they can detect reverse gradients.

\section{AN EMPHASIS ON RELATIVE OR ABSOLUTE MEASURES OF INEQUALITY?}

There are very important but often unrecognised normative assumptions made when in the choice of reporting an absolute or a relative measure of inequality. As illustrated in this review, an absolute measure of inequality incorporates information on differences in the observed death rate between the groups compared in the study. For example, if the age adjusted mortality rate for men in a given country is twice that of women and the ratio of mortality rates between the top and bottom income quintiles is identical for men and women, the summary measure of inequality, applying an absolute measure, will be greater for men than for women. Using the same empirical example, the summary measure of inequality, applying a relative measure, would report approximately identical inequality measures for men and for women.

This fundamental difference between the families of relative and absolute measures of inequality is not well understood in the research and policy research literature. Absolute measures of inequality are based on direct measures of health, such as the rate of death per 1000 population. Relative measures of inequality are dimensionless, calculated as the value of the absolute measure of health divided by the mean value of health for a reference group. This means that whereas all deaths are of equal value for comparisons based on absolute measures, they are valued as a function of the health of the reference group when a relative measure is used. In the work reported in this paper, male deaths are assumed to be less significant when estimated using relative inequality measures because they are more common than female deaths. Absolute measures may therefore be more appropriate for policy purposes, where the population impact of health policy investments may be the principal objective. Relative measures, on the other hand, may be more appropriate to objectives that seek to understand aetiology and the mechanism of interventions.

In conclusion, this review may contribute to resolving uncertainty about whether position in a socioeconomic hierarchy confers different mortality risks on men and women. The findings of this review indicate that inferences about health inequalities between groups or across time are sensitive to the choice of the inequality measure. Wider understanding of this methodological issue would improve the clarity of the reporting and synthesis of evidence on the magnitude of health inequalities in populations.

\section{Authors' affiliations}

C A Mustard, Department of Public Health Sciences, University of Toronto Faculty of Medicine

C A Mustard, J Etches, Institute for Work \& Health, Toronto, Canada C A Mustard, Population Health Program, Canadian Institute for Advanced Research

A previous version of this paper was presented to the Second International Conference of the International Society for Equity in Health, Toronto, Canada June 2002 and to the International Epidemiology Association meetings, Montreal, Canada, August 2002.

\section{REFERENCES}

1 Koskinen S, Martelin T. Why are socioeconomic mortality differences smaller among women than among men? Soc Sci Med 1994;38:1385-96.

2 McDonough P, Williams DR, House JS, et al. Gender and the socioeconomic gradient in mortality. J Health Soc Behav 1999;40:17-31.

3 Vågerö D. Health inequalities in women and men. BMJ 2000;320:1286-7.

4 Krieger N, Williams DR, Moss NE. Measuring social class in US public health research: concepts, methodologies and guidelines. Annu Rev Public Health 1997; 18:341-78.

5 Macintyre S, Hunt K. Socio-economic position, gender and health: how do they interact? Journal of Health Psychology 1997;2:315-34.

6 Anand S, Diderichsen F, Evans T, et al. Measuring disparities in health: methods and indicators. In: Evans T, Whitehead M, Diderichsen F, et al. Challenging inequalities in health: from ethics to action. Toronto: Oxford University Press, 2001.

7 Etches J, Mustard CA. Summary measures of social inequality in health Working paper number 198 Toronto: Institute for Work \& Health, 2003.

8 Mackenbach JP, Kunst AE. Measuring the magnitude of socio-economic inequalities in health: an overview of available measures illustrated with two examples from Europe. Soc Sci Med 1997;44:757-71.

9 Manor O, Matthews S, Power C. Comparing measures of health inequality. Soc Sci Med 1997;45:761-71.

10 Wagstaff A, Paci P, van Doorslaer E. On the measurement of inequalites in health. Soc Sci Med 1991;33:545-57.

11 Kaufman JS, Long AE, Liao Y, et al. The relation between income and mortality in US blacks and whites. Epidemiology 1998;9:147-55.

12 Markides KS. Consequences of gender differentials in life expectancy for black and Hispanic Americans. Int J Aging Hum Dev 1989;29:95-102.

13 Park KA, Clifford WB. Sex differentials in cardiovascular mortality: an ecological analysis. Soc Sci Med 1989;29:869-76.

14 Wingard DL, Suarez L, Barrett-Connor E. The sex differential in mortality from all causes and ischemic heart disease. Am J Epidemiol 1983;117:165-72.

15 Wunsch G, Duchene J, Thiltges E, et al. Socio-economic differences in mortality. A life course approach. European Journal of Population 1996;12:167-85.

16 Wilkins R, Adams O, Brancker A. Changes in Mortality by income in Urban Canada from 1971 to 1986 . Health Rep 1991;1:37-174.

17 Goldblatt P, Fox J, Leon D. Mortality of employed men and women. Am J Ind Med 1991;20:285-306.

18 Sorlie PD, Backlund E, Keller JB. US Mortality by economic, demographic and social characteristics: the National Longitudinal Mortality Survey. Am J Public Health 1995;85:949-56.

19 Feldman JJ, Makuc DM, Kleinman JC, et al. National trends in educational differentials in mortality. Am J Epidemiol 1989;129:919-33.

20 Elo IT, Preston SH. Educational differentials in mortality: United States 197985. Soc Sci Med 1996;42:47-57.

21 Pappas G, Queen S, Hadden W, et al. The increasing disparity in mortality between socioeconomic groups in the United States, 1960 and 1986. N Engl J Med 1993;329:103-9.

22 Millar WJ. Sex differentials in mortality by income level in urban Canada. Can Public Health 1983;74:329-34.

23 Pamuk ER. Social class and inequality in mortality from 1921 to 1972 in England and Wales. Population Studies 1985;39:17-31.

24 Anderson RT, Sorlie PD, Backlund E, et al. Mortality effects of community socioeconomic status. Epidemiology 1997;8:42-7.

25 Sundquist J, Johansson SE. Self reported poor health and low educational level predictors for mortality: a population based follow up study of 39,156 people in Sweden. J Community Health 1997;51:35-40.

26 Koskenvuo M, Kaprio K, Kesaniemi A, et al. Differences in mortality from ischemic heart disease by martial status and social class. Journal of Chronic Diseases 1980;33:95-106.

27 Backlund E, Sorlie PD, Johnson NJ. The shape of the relationship between income and mortality in the United States: evidence from the National Longitudinal Mortality Study. Ann Epidemiol 1996;6:12-20.

28 Smith KR, Waitzman NJ. Effects of marital status on the risk of mortality in poor and non-poor neighborhoods. Ann Epidemiol 1997;7:343-9. 
29 Otterblad Olausson P. Mortality among the eldery in Sweden by social class. Soc Sci Med 1991;32:437-40.

30 Valkonen T. Adult mortality and level of education: a comparison of six countries. In: Fox J, ed. Health inequalities in European countries. Aldershot: Gower, 1989:142-60.

31 Wing S, Casper M, Hayes CG, et al. Changing association between community occupational structure and ischaemic heart disease mortality in the United States. Lancet 1987;ii:1067-70.

32 McLoone P, Boddy FA. Deprivation and mortality in Scotland, 1981 and 1991. BMJ 1994;309:1465-70.

33 Luoto R, Prattala R, Uutela A, et al. Impact of unhealthy behaviors on cardiovascular mortality in Finland, 1978-1993. Prev Med 1998;27:93-100.

34 Hemstrom O. Is marriage dissolution linked to differences in mortality risks for men and women? Journal of Marriage and the Family 1996;58:366-78.

35 Koskenvuo M, Sarna S, Kaprio K, et al. Cause-specific mortality by marital status and social class in Finland during 1969-1971. Soc Sci Med 1979:13A:691-7.

36 Morris JN, Blane DB, White IR. Levels of mortality, education, and social conditions in the 107 local education authority areas of England. J Epidemiol Community Health 1996:50:15-17.

37 Martelin T. Mortality by indicators of socioeconomic status among the Finnish elderly. Soc Sci Med 1994;38:1257-78.

38 Gregorio DI, Walsh SJ, Paturzo D. The effects of occupation-based social position on mortality in a large American cohort. Am J Public Health 1997:87:1472-5.

39 Hemstrom 0 . Does the work environment contribute to excess male mortality? Soc Sci Med 1999:49:879-94.

40 Pekkanen J, Tuomilehto J, Uutela A, et al. Social class, health behaviour and mortality among men and women in eastern Finland. BMJ 1995;311:589-93.

41 Backlund E, Sorlie PD, Johnson NJ. A comparison of the relationship of education and income with mortality: The national longitudinal mortality study. Soc Sci Med 1999;49:1373-84.
42 Vagero $D$, Lundberg $O$. Socio-economic mortality differentials among adults in Sweden. Adult mortality in developed countries. Oxford: Oxford University Press, 1995:223-42.

43 Pettiti DB. Meta-analysis, decision analysis and cost-effectiveness analysis. New York: Oxford University Press, 1994

44 Vallin, J. Can sex differentials in mortality be explained by socio economic mortality differentials? In: Lopez AD, Caselli G, Valkonen T, eds. Adult mortality in developed countries: from description to explanation. Oxford: Clarendon Press, 1995:179-200.

45 Waldron I. The contribution of smoking to sex differences in mortality. Public Health Rep 1986;101:163-73.

46 Berkman LF, Syme SL. Social networks, host resistance and mortality: a nineyear follow-up study of Alameda County residents. Am J Epidemiol 1979:109:186-204.

47 Orth Gomer K, Johnson JV. Social network interaction and mortality: a six year follow up of a random sample of the Swedish population. Journal of Chronic Diseases 1987;40:949-57.

48 Blazer DG. Social support and mortality in an elderly community population. Am J Epidemiol 1982;115:684-94.

49 House JS, Robbins C, Metzner HL. The association of social relationships and activities with mortality: prospective evidence from the Tecumseh Community Health Study. Am J Epidemiol 1982;116:123-40.

50 Kaplan GA, Salonen JT, Cohen RD, et al. Social connections and mortality from all causes and from cardiovascular disease: prospective evidence from eastern Finland. Am J Epidemiol 1988;128:370-80

51 Seeman TE, Berkman LF, Blazer D, et al. Social ties and support and neuroendocrine function: the MacArther studies of successful aging. Ann Behav Med 1994:16:95-106.

52 Umberson D, Chen MD, House JS, et al. The effect of social relationships on psychological well-being; are men and women really so different? American Sociological Review 1996;61:837-57.

53 Makela P Valkonen T, Martelin T Contribution of deaths related to alcohol use to socioeconomic variation in mortality: register based follow up study. BMJ 1997:315:211-16.

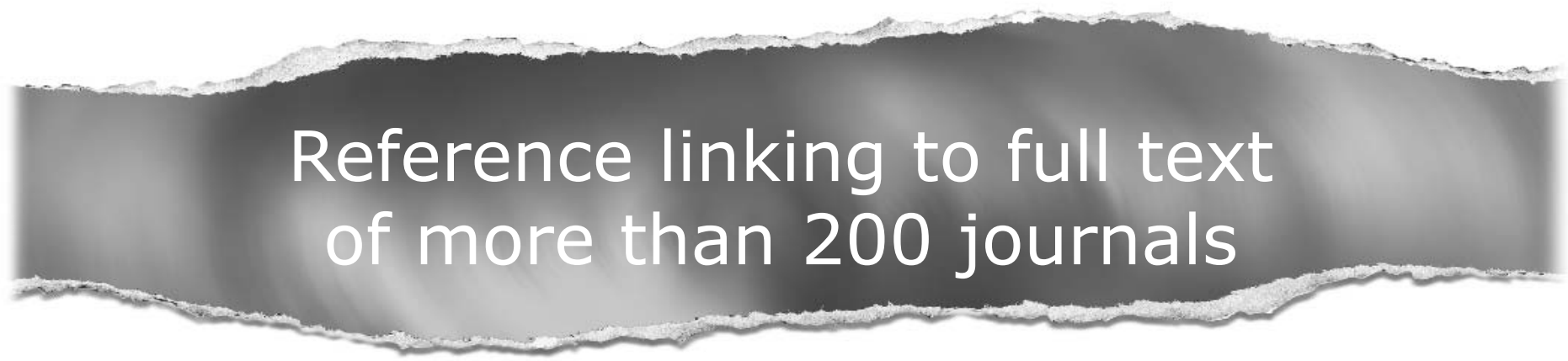

Toll free links

You can access the FULL TEXT of articles cited in the Journal of Epidemiology and Community Health online if the citation is to one of the more than 200 journals hosted by HighWire (http://highwire.stanford.edu) without a subscription to that journal.

There are also direct links from references to the Medline abstract for other titles.

www.jech.com 